\title{
Experimental Study on the Change of Mechanical Properties of Mechanism Sand Mortar Subjected to High Temperature
}

\author{
Hai-jing $\mathrm{Xu}^{1,}$, Cheng-xian $\mathrm{Cen}^{1, \mathrm{~b}}$ \\ ${ }^{1}$ School Architecture and Transportation Engineering, Guilin University of Electronic Technology, \\ Guilin, 541004, China \\ a909918240@qq.com, b39353588@qq.com
}

Keyword: Mechanism sand mortar, High temperature, Mechanical properties, Elastic modulus

\begin{abstract}
The change laws of mechanical properties of mechanism sand mortar subjected to high temperature were studied on the paper. The study shows that: (1) The strength of mechanism sand mortar, subjected to high temperature, was reduced with the rise of temperature. When the temperature was below $500{ }^{\circ} \mathrm{C}$, the change is small and the strength was significantly reduced when the temperature was high more than $500{ }^{\circ} \mathrm{C}$, (2) The elastic modulus of mortar also decreased with the increase of temperature, when the temperature was below $300{ }^{\circ} \mathrm{C}$, the elasticity modulus reduced smaller, but the temperature exceeds $500{ }^{\circ} \mathrm{C}$, the elastic modulus was dropped rapidly.
\end{abstract}

\section{Introduction}

Mortar is one of the bonded materials commonly used in civil engineering. It is suffered from load, temperature, etc. which carrying on the masonry structure. The strength of the mortar will directly affect the stability and safety performance of the masonry structure. Mechanical properties of mortar suffering high temperature were studied by the people.

Xiao-yan xu, etc [1] who studied on the change of mechanical properties of the high-grade cement mortar which was impacted different temperatures and different cooling ways founded that the pressive strength of high-grade cement mortar gradually decreased with the rise of temperature. Strength fell smaller when the temperature was below $300{ }^{\circ} \mathrm{C}$ and decreased significantly when the temperature was exceed $450{ }^{\circ} \mathrm{C}$. Liu wei, etc [2] researched the changes of pressive strength of mortar with temperature changes and different temperature cycles. Zheng-fa, etc [3] Chen studied on the strength and durability of concrete of mechanism sand under high temperature. Xian-yang zhang, etc [4] analyzed the test data of mortar strength degradation under high temperature and forecast the mortar strength degradation by using grey prediction model. It was proved the possibility for using grey prediction model forecast the mortar strength degradation under high temperature

Natural sand as short-term non-renewable material is one of the main material of mortar. Existing resources of natural sand has not fully meet the needs of engineering construction and mechanism sand instead of natural sand is inevitable trend The change of strength which has been subjected to high temperature was researched on mainly mortar of the natural sand or the concrete of mechanism sand. Mechanism mortar was less studied. Mechanical properties change of mechanism sand mortar which subjected to different temperature is studied through experiments in this paper.

\section{Experimental Materials and Specimen}

\section{Experimental Materials.}

Cement. Experimental cement of the strength grade 425 is the Production of composite Portland cement by Xing-an conch cement co.

Sand. The mechanism sand is crushing by cobble of Guilin. The parameter of sand grading is got through the sieve analysis experiment and not admixture. 
Specimen of Mortar. Three grades of strength (M20, M25 and M30) were studied in the experiment and block size of specimen are also $70.7 \mathrm{~mm} \times 70.7 \mathrm{~mm} \times 70.7 \mathrm{~mm}$. Mortar mixing material were prepared in the laboratory, using artificial machinery stirring. Mixing equipment and mixing time was conformed to the regulation of Standard for Test Method of Basic Properties of Construction Mortar (JGJ/T 70-2009).

Mixing ratio of mortar was calculated and determined in accordance with the regulation of Specification of Mix Proportion Design of Masonry Mortar(JGJ/98-2010). First of all, trial-mix strength of mortar, the dosage of the cement and the sand in the mortar of Per cubic metre was calculated according to the selection of mortar strength grade and then the water consumption was selected by the consistency of mortar (Table1). The specimen was maintenance naturally at room temperature for 28 days.

Table 1. Mechanism sand mortar mix ratio of different strength grade.

\begin{tabular}{|c|c|c|c|}
\hline Strength grade & $\begin{array}{c}\text { Consumption of cement } \\
\left(\mathrm{kg} / \mathrm{m}^{3}\right)\end{array}$ & $\begin{array}{c}\text { Water consumption } \\
\left(\mathrm{kg} / \mathrm{m}^{3}\right)\end{array}$ & $\begin{array}{c}\text { Mixing ratio } \\
\text { Cement:Sand:Water }\end{array}$ \\
\hline M20 & 380 & 300 & $1: 4.21: 0.79$ \\
\hline M25 & 410 & 300 & $1: 3.90: 0.73$ \\
\hline M30 & 480 & 300 & $1: 3.33: 0.63$ \\
\hline
\end{tabular}

\section{The Experimental Method}

Heating of Mortar. The specimens were heated by the Sx2-2.5-10 box type resistance furnace with heating chamber size of $200(\mathrm{~mm}) \times 120(\mathrm{~mm}) \times 80(\mathrm{~mm})$. The heating temperature on the specimen of the experiment include the room temperature, $100{ }^{\circ} \mathrm{C}, 200{ }^{\circ} \mathrm{C}, 300{ }^{\circ} \mathrm{C} . . .900{ }^{\circ} \mathrm{C}$. Mortar specimens were heat to the predetermined temperature in the resistance furnace and keep the temperature for 120 minutes, then open the lid of the stove, cooling with natural cooling way.

Load Test. Compressive test was done after specimens cooling to room temperature for more than 7 days. The test was done by the hydraulic universal tester with the loading rate was $0.5 \mathrm{~mm} / \mathrm{min}$.

\section{The Experimental Results}

The Change of Strength. The change of strength of Mechanism sand mortar with temperature was shown in Fig. 1. The pressive strength of the mortar decreased gradually with heating temperature increases, especially when the temperature over $500{ }^{\circ} \mathrm{C}$, strength fell obviously and loss more than $50 \%$. When the temperature over $900{ }^{\circ} \mathrm{C}$, the mortar has been completely destroyed. Changes of strength of different grade mortar with the temperature changing were consistent. The result can be fitting of polynomial curve. The rules can be described by the same formula:

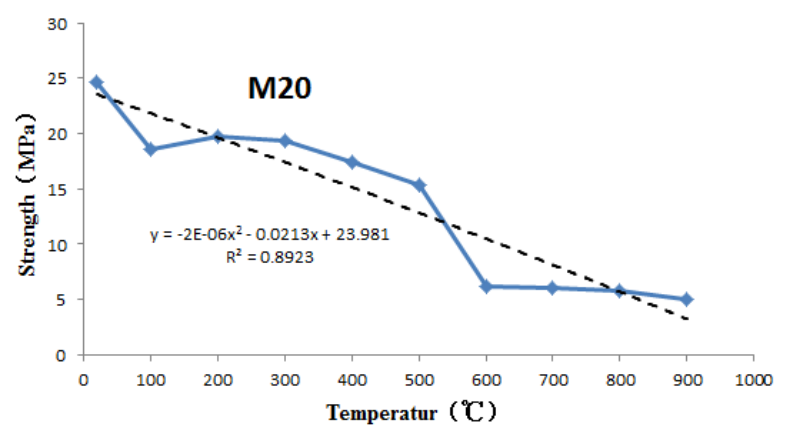

(a)

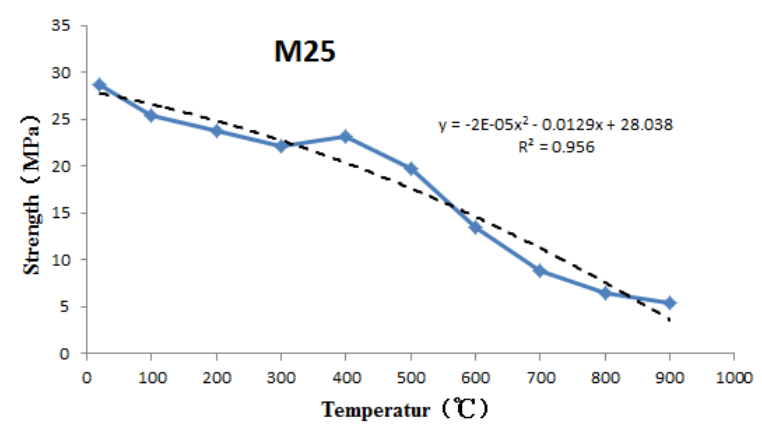

(b) 


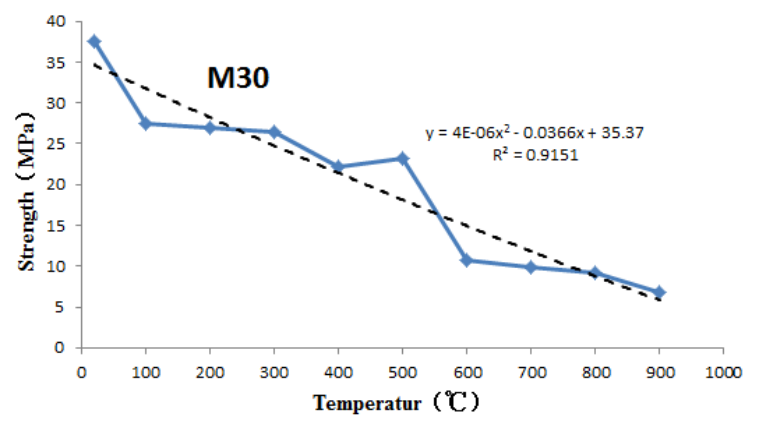

(c)

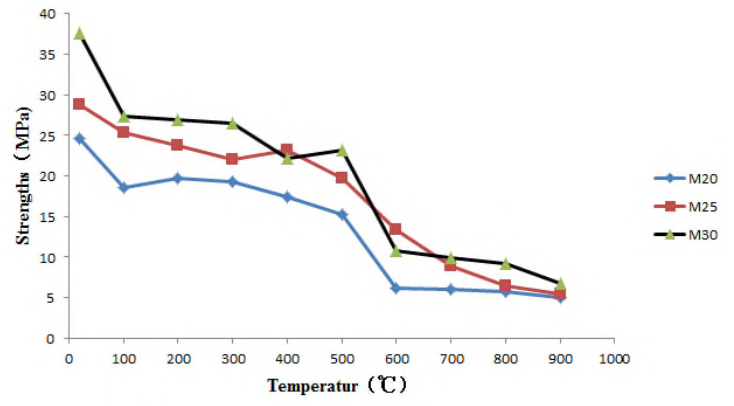

(d)

Fig. 1 The change of strength of different grade mortar with temperature variation.

$$
y=a x^{2}+b x+c
$$

where, $\mathrm{y}$ is representing strength of mortar, $\mathrm{x}$ is temperature, $\mathrm{a}, \mathrm{b}$ and $\mathrm{c}$ are material constants which are different of different grade strength of mortar.

The Change of Elastic Modulus. The change of elastic modulus of Mortar with temperature was shown in Fig. 2. Through graph, the elastic modulus of mortar decline with the increase of heating temperature. When the temperature was Less than $300{ }^{\circ} \mathrm{C}$, variation of the elastic modulus is relatively small. When the temperature over $500{ }^{\circ} \mathrm{C}$, elastic modulus is decrease rapidly. Different level of elastic modulus of mortar has the same change rule with the change of temperature fitting by the method of polynomial. The rules can be described by the same formula:

$$
E=A T^{2}+B T+C
$$

where, $\mathrm{E}$ is the elastic modulus of mortar, $\mathrm{T}$ is temperature, $\mathrm{A}, \mathrm{B}$ and $\mathrm{C}$ are material constants which are difference of different grade strength of mortar and can be got by experiment.

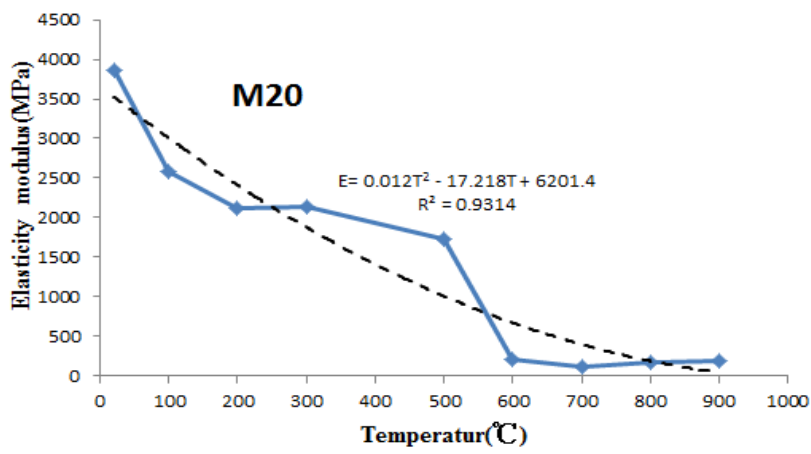

(e)

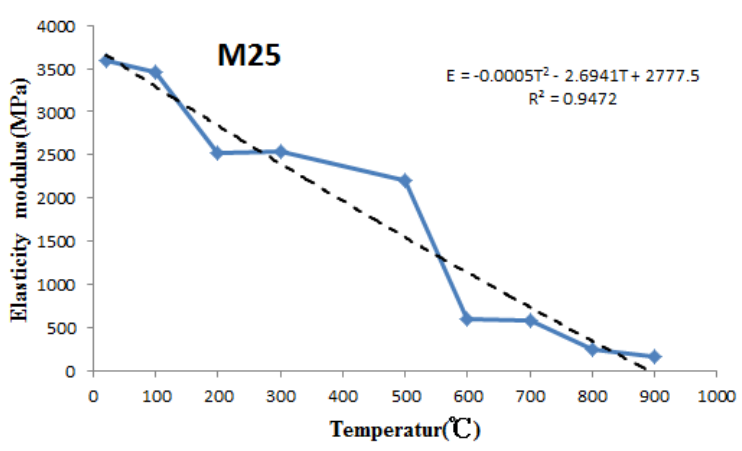

(f)

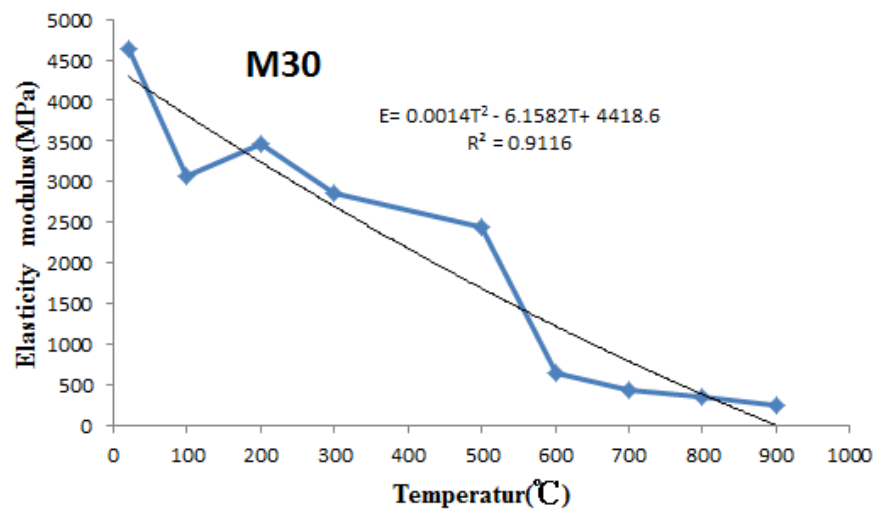

( $(\mathrm{g})$

Fig. 2 The change of elastic modulus of different grade mortar with temperature variation. 
Mass Loss of Specimen. Mass of each specimen must be measured first, and then heat in the furnace. The surface of Each specimen was clean after heating and measured the body mass and finally the mass loss rate is calculated by follow,

$$
p=\frac{m_{1}-m_{2}}{m_{1}} \times 100 \%
$$

where, $m_{1}$ is the body mass of specimen before heating and $m_{2}$ is the body mass of specimen after heating.

There was obviously fracture damage on the surface of the specimen under the effect of temperature stress in the figure, resulting in the mass loss of the specimens. Mass loss rate of specimen was gradually increasing with the increase of heating temperature (Fig. 3).

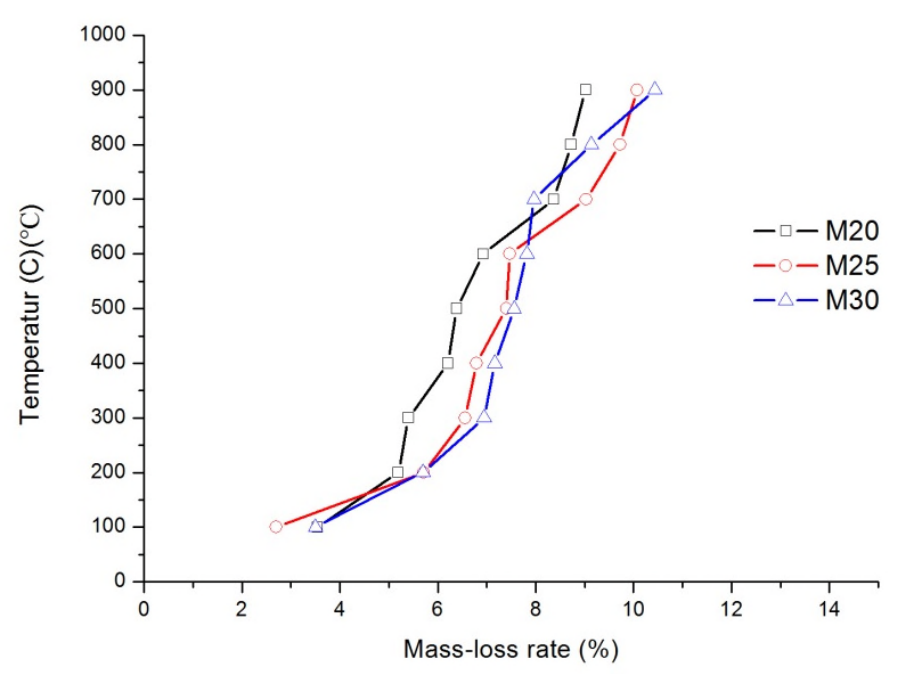

Fig. 3 The change of elastic modulus of different grade mortar with temperature variation.

\section{Conclusion}

High temperature heating experiment of mechanism sand mortar was carried out in this paper and the paper also stated the strange of the mechanical properties of mechanism sand mortar under different temperature. Through the analysis of the results of the experiment in paper, conclusion can be got for the following:

(1) The strength of mechanism sand mortar, subjected to high temperature, was reduced with the rise of temperature. When the temperature was below $500{ }^{\circ} \mathrm{C}$, the change is small and the strength was significantly reduced when the temperature over $500{ }^{\circ} \mathrm{C}$.

(2) The elastic modulus of mortar also decreased with the increase of temperature, when the temperature was below $300{ }^{\circ} \mathrm{C}$, the elasticity modulus reduced smaller, but the temperature exceeds $500{ }^{\circ} \mathrm{C}$, the elastic modulus was dropped rapidly.

(3) Mass loss rate of specimen of mechanism sand mortar was gradually increasing with the increase of heating temperature.

\section{References}

[1] X. Y. Xu, G. L. Yuan, L. Y. Cheng, X. Y. Zhang. Experimental Study on the Effect of High Temperature on the Strength of High-strength Cement Mortar. J. Shandong Univ. Sci. Tech (Natural Science), 28(5) (2009) 35-38.

[2] L. Wei, L. X. Xiong, H. F. Pan. Mechanical Properties of Cement Mortar under High Temperature Cycles. Bull. Chinese Ceram. Soc. 35(7) (2016) 2314-2317. 
[3] Z. F. Chen, G. F. Liu, J. M. Xu. Study on the Strength and Durability of Concrete with Manufactured- sand Under Condition of High Temperature. Concrete (Material and Adminicle), (264) (2011)46-48.

[4] X. Y. Zhang, Y. J. Song, L. Y. Cheng. The Grey Predicting Model of the Mortar Pressive Strength after the High Temperature. Shanxi Architecture, 34(12) (2008) 172-173. 